\title{
WAYS OF KNOWING IN DOCTORAL EXAMINATION: HOW WELL IS THE DOCTORAL REGIME?
}

\begin{abstract}
:
The article draws on findings from the PhD Examination Project at the SORTI Research Centre of The University of Newcastle, Australia. It focusses on an analysis of the roles of examiner and supervisor, in relation to the candidate, as seen through the lens of Habermas's 'Ways of Knowing' theory. On the basis of this, it has been postulated that the dominant text in the $\mathrm{PhD}$ examination process may work to constrain the generation of new knowledge rather than encourage it. The paper explores practical implications for research training and questions the current wellbeing of the doctoral regime.
\end{abstract}




\section{Introduction}

Increasing concern for quality control and transparency of higher education processes have led to increased scrutiny in the field. Included in this scrutiny has been an interest in the processes surrounding the phenomenon of the doctorate. The work of the Centre for the Study of Research Training and Impact (SORTI) at The University of Newcastle, Australia, is best understood as part of this growing interest. Among the Centre's newly completed projects is the 'PhD Examination Project', supported by an Australian Research Council Grant. The study is based on examiner report data from eight Australian universities that were selectively sampled to represent research intensiveness and breadth of research activity. In Australia the completed doctorate is presented in written form as a thesis. Typically, the thesis is sent to two or three examiners external to the University, with about half going overseas (Pitkethly \& Prosser, 1995; Bourke et al., 2004). In most cases, there is no attached coursework or oral examination, so the 'blind refereeing' format of the examination constitutes the entire evaluation of doctorate quality and worth. The text of examiner reports provides an opportunity to explore what the structures and quality of reports can tell us about examiner roles in relation to examination process. We hypothesized that, in their reports, examiners are consciously positioning themselves in relation to knowledge - what it is to know, how they 'know', what it is important to know and why. Examiners, as members of a particular group, share a familiar set of common-sense understandings about research at the $\mathrm{PhD}$ level and what is acceptable. Such understandings (or at least the interpretative repertoire they draw on to express them) is captured in what they say about examination in their reports (Holbrook et al., 2004a, Holbrook et al., 2004c). That the examination process in Australia relies entirely on the evaluation of a dissertation by parties otherwise uninvolved in its generation, and that there is no opportunity for the candidate to interact with the examination group, are important considerations in examining report texts. It is also very relevant to an issue taken up in this paper, namely, the tendency towards lack of communicative knowing that is evident in the examiner reports.

The overall aim of the investigation is to develop new, strategic and significant knowledge for research pedagogy and assessment, especially as they pertain to research training. This article outlines some of the key findings from the 'core' content analysis phase of the investigation. More specifically, it reports on the analysis that focussed on the nature of examiner response based on the 'position' taken by examiners in their written reports, courtesy of the 'Ways of Knowing' thesis of Jurgen Habermas (1972; 1974). Habermas proposed that there was a consistent pattern through which knowledge was developed, revealed and further negotiated. According to his thesis, this pattern was to be found in all areas of knowledge and across disciplinary boundaries. He argued that this consistent pattern arose from three different 'cognitive interests', which in turn impelled three associated 'ways of knowing'. First, there is empirical/analytic knowing, impelled by the cognitive interest for control of the 'content', or 'facts and figures' dimension, of knowledge. Second, is historical/hermeneutic knowing, impelled by the cognitive interest for understanding the 'interpretive', 'meaning' or 'communicative' dimensions of knowledge. Third, is critical or self-reflective knowing, impelled by the cognitive interest to be emancipated from the past and so to be free to investigate, explore and to draw one's own conclusions about the content and meaning of knowledge. This third way of knowing is ultimately about breaking new boundaries of knowledge, including coming to renewed knowledge of self. Furthermore, according to the thesis, these apparent divisions in the way knowledge develops arise from human perception, rather than originating in any inherent partitioning within knowledge itself. For a project with the goal of identifying and defining patterns of research higher 
degree examination across discipline areas, this presented as an ideal thesis by which analysis might proceed. Preliminary work of this kind was performed on the reports emanating from the initial institution (cf. Lovat, 2004) and then extended as the study grew to take in other institutions (Lovat et al., 2004).

Habermas's 'Ways of Knowing' theory suggests the need for breadth ('empirical/analytic' method), depth ('historical/hermeneutic' method) and, in order for complete knowing to be achieved, the need for an analysis that conforms with 'self-reflectivity'. Examiners of the $\mathrm{PhD}$ are assessing the potential of the candidate in terms of their demonstration of scholarly qualities in relation to their research project, as well as the quality of the project and its outcomes, including its contribution to the field of inquiry. Judgement about this has to come from within specific communities of scholars with particular expertise in the subject matter and approach of the thesis. This is what Elton (2004) describes as an "interpretive community of assessors” (p. 54).

We argue that Habermasian theory provides a lens by which assessment intentions and assumptions can be appraised, differentiating between assessment that is addressed purely to a technical ('empirical/analytic') regime of knowing from that addressed to interpretive ('historical/hermeneutic') forms of knowing and, furthermore, from those regimes of assessment that might be seen as attempting to deal meaningfully with the kind of knowing that Habermas refers to as 'self-reflective'. Granted Habermas's estimation of the latter as being the kind of knowing that releases the knower from the past and engages the knower in new forms of knowing and action, one could not over-state the relevance of this knowledge and its attached assessment forms to a project which is focussed on a stage of learning widely held to be about the 'original' and the 'creative', with the $\mathrm{PhD}$ product allegedly being judged by how far it stretches the boundaries of current knowing.

After a brief review of the literature, the article will provide the details and findings about the content analysis phase that lay at the core of the study. We will then present the epistemological and methodological positions that shaped the more intensive and extended text analysis concerned with examiner positioning (Lovat, 2004; Lovat et al., 2004; Monfries \& Lovat, 2006). In the final section, we speculate on ramifications for the practicalities of research training in general and supervision in particular, should the application being made of the Habermasian theory continue to prove tenable.

\section{Background}

In the review of the literature that underpinned the project, we identified that research on $\mathrm{PhD}$ examination was slight and exploratory at best. The samples used were relatively small and the studies, while useful, were more preliminary than definitive. Methods were also mixed, often rendering studies non-comparable with each other. For instance, some studies had drawn on interviews and surveys with examiners, supervisors and students, while others had observed examination proceedings. Still others proceeded by collecting the text of examiner reports in an attempt to elicit what examiners were looking for in a thesis. Kouptsov (1994) engaged in an early UNESCO-sponsored cross-national survey among European institutions, while Johnston (1997) centred his work on 51 examiner reports from one university. Meanwhile, Tinkler and Jackson (2000, 2001) and Jackson and Tinkler (2001) investigated the English approach to PhD examination. Their study was across 20 institutions drawn from a mixture of old and new universities with an ancillary study from two of those universities centred on questionnaire responses from 100 examiners and candidates. Pitkethly and 
Prosser (1995) contributed to an early Australian study that drew on 74 thesis reports at one university, while Mullins and Kiley’s (2002) work in Australia drew on reports from 30 examiners from across a number of universities. Common findings from all these studies included a general concurrence among all parties about the key criteria that should apply to the successful doctorate, namely that the work should be original and that it should be seen to be making a contribution to knowledge. However, just what was meant by these central concepts was not so clear nor necessarily agreed across the studies.

The studies also revealed that expectations about standards to be applied to good, satisfactory and unsatisfactory products were far from universal. Both studies by Pitkethly and Prosser (1995) and Johnston (1997) noted a tendency on the part of examiners to treat the product of a thesis as being a virtual gateway to scholarly status and therefore as being an ultimate expression of scholarship. Yet the evidence was that failure in the doctorate was rarely considered an option. In their study focussed on interviews with experienced Australian examiners, Mullins and Kiley (2002) noted that examiners appeared very clear in the distinctions they made between poor, acceptable and outstanding theses, but they also detected that examiners went into the process anticipating that students would pass. In the 303 examiner reports that constituted the data of an early report in the SORTI study (Holbrook et al., 2004), only two examiners recommended a grade of fail.

Beyond the differences between examiner judgments, institutions themselves were seen to vary in the standards they set and the guidelines they offered to examiners. Tinkler and Jackson (2000) identified considerable procedural variations and expectations in the ways that English universities went about offering guidelines to examiners. They also commented that they detected a tendency for guidelines to be generally vague in they way they were expressed, almost as though institutions themselves were not clear about the standards they were applying. In Australia, Mullins and Kiley’s (2002) data taken from examiner interviews suggested that examiners took little notice of guidelines anyway, tending rather to establish their own criteria for assessment.

The major findings emanating from the research above presented a picture of standards that differ across universities and even within universities, and in the processes by which the doctorate is planned, conducted, supervised and examined. Assessment was seen as a particular problem, partly owing to the above, but also in part to the very conceptions about the way it should be done. This signalled a particular issue around examination and the likelihood of there being sufficient lack of clarity, if not downright confusion, about the very purpose of the doctorate. A sample of examiners in a study by Denicolo (2003) showed, at the same time, a high level of consensus around the belief that doctoral work connoted quality, but a low level of consensus about how this quality should be assessed.

In more recent work (Bourke et al., 2007 in press; Holbrook \& Bourke, 2004; Holbrook et al., 2004c; Holbrook et al., 2007 in press; Kiley \& Mullins, 2004; Lawson et al, 2003; Morley et al., 2002; Shaw \& Green, 2002; Trafford 2003), there has been an effort to engage in sustained analysis of issues around standards and quality in regard to the doctoral process, and especially concerning the examination phase of the process. In our own study, this has centred particularly on the text of the examination report as well as on the links between the text of the report and the examination outcome. By such analysis, the intention has been to understand better all the subtleties of the process, including what mindset and intentions the examiner takes into the process. Examiner reports framed against examiner recommendation 
has been seen to provide an ideal window into issues of consensus, or the lack thereof, and expectations about quality.

\section{Approach}

The scope of the project is explained fully elsewhere (Holbrook \& Bourke, 2004). The text preparation and analysis is the focus here. Each report (de-identified by the participating institution) was scanned and entered into QSRN6 qualitatitive data analysis software in a form that yielded standardized line lengths. On average, the reports were 2.5 pages long, totalled 2121 in number and represented 804 candidates. We collected a complete set of reports for each candidate. The coding and early validation stages focussed on the content of $150 \mathrm{PhD}$ examination reports from one institution. Line-by-line coding provided five 'parent' categories of information and five times as many sub categories that provided the basis for further navigation and analysis.

The parent nodes comprised:

- report organization that appraised the distinctive ways in which examiners structured the report

- $\quad$ examiner and process that captured the different ways in which the examiner seemed to approach the whole task of examination

- assessable areas that captured the different areas examiners identified such as literature use, analysis or communicative competence

- dialogic elements that identified the various ways in which the examiner engaged with the candidate through the examination report, and

- evaluative elements that captured the heart of appraisal and judgement about the validity, worth and original contribution of the thesis under examination.

The categories were tested for reliability across a further 150 examination reports from the same institution and subsequently checked against an additional 300 reports from a second institution. Inter-coder agreement was $90 \%$ and was guided by a coding manual that grew and reflected the emergence of new categories or text illustrations of existing categories as data from new institutions was added.

Analysis comprised textual description at one end and high level inference at the other. Textual description relied on a faithful rendering of the text against the selected categories, while high level inference went well beyond the text to speculate on underlying reasons for incidences of occurrence, preponderance and conjunctions of textual type. In the middle was a form of low level inference where reasons for such incidences were self-evident or 'disclosed' by the examiners. We discovered significant differences in comment (expressed as a proportion of total length of a report, see Bourke et al., 2004) between highest level theses and marginal theses (those that required significant correction). This provided us with a framework for sampling the text to pursue a more intensive analysis of examiner 'disclosure', how it was framed within the report, its link to judgement and, drawing particularly on the evaluative elements of the text, how examiners were representing process and their role within it.

\section{The core emphases in examiner text}

The range of categories identified and coded are presented in Table 1 which also shows their occurrence in the 2121 examiner reports on two bases, First, the proportion of reports where there was at least one instance of the category is shown and, second, the average proportion 
of a report given over to that category. As can be seen in the Table, multiple codings were possible and were, in fact, the norm, with an average of almost two codes per line.

\section{[INSERT TABLE 1 HERE]}

In the 'examiner and process' category, 61\% of reports provided some direct indication of the criteria that examiners were using in structuring their reports and this comprised, on average, $5 \%$ of a report. Furthermore, in 50\% of reports, some indication was given about the examiner's own personal and professional context, also at 5\%. These features were more often than not found in conjunction with each other. Our reading of this is that examiners felt that saying something about their qualification to examine the thesis, their strengths or their current research illuminated the criteria they were privileging. This was an early clue to the degree of subjectivity, if not idiosyncrasy, to be found in the examination report.

In 'assessable areas covered', it became evident that the disciplinary background of the thesis and/or examiner provided for some persistent differences within an overall framework of consistency across disciplines. For example, while $95 \%$ of all reports were preponderantly focussed on addressing the findings of the thesis, on average this constituted about $20 \%$ more of the scientifically-based reports than those of business and arts. Similarly, while $38 \%$ of all reports contained some idiosyncratic addressing of a particular feature of the thesis, normally around engaging in depth with a particular finding or making extended comment about sources, such a feature tended to be only one-third the proportion of a report in health as in the arts and social sciences. Again, while the approach and design of the study is mentioned in $81 \%$ of all reports, it is a less pervasive feature of an engineering report than of reports in education, business, law and health. Findings in this category balanced those in the examiner and process category above by modifying attention to examiner subjectivity with sensitivity to disciplinary difference. At the same time, disciplinary difference was not so significant that it could outweigh the overall consistency across disciplines of the ways in which examiners carve up a thesis for examination (see also Bourke et al. 2004).

In 'dialogic elements', it was found that examiners used the first person at least on one occasion in $89 \%$ of the reports under investigation but, in most reports, the use was not sustained, comprising an average of only $17 \%$ of the text. That reports are largely formal documents is borne out by the fact that conversational tone was less common, found in only $30 \%$ of the reports and comprising only 3\% of text. In terms of the phrasing used by examiners, 'Intellectual Engagement' (defined as intensity of engagement represented as 'excitement' with the substance of the thesis) was even less common, being found in only $21 \%$ of reports but also comprising 3\% of text. When combined with the findings emanating from 'evaluative elements', we find that genres like conversation and the kind of open dialogue also indicative of intellectual engagement are well and truly outweighed by more formal summative and formative comment. For example, the judgement referred to as formative instruction was to be found in $63 \%$ of reports and constituted no less than $21 \%$ of text, while summative comment was found in some form in almost all reports (97\%) and constituted $25 \%$ of text. While most comment and judgment was positive or neutral, negative summation and judgment occurred in 33\% and 32\% of reports. This was interesting because the total sample represented such high levels of ultimate success, there being less than one percent of examiner reports that recommended failure and only one thesis that finally failed. Hence, it was surmised that there may well be a patterned assumption about the PhD report that determines some of the tone, regardless of the fact that the object of comment represents the peak of higher education productivity and is marked by overwhelming success rates. This 
surmise became an early clue to the later strand of investigation that lies at the heart of this paper's findings.

This renewed understanding about the interface between the quality of a thesis, the textual characteristics of the accompanying reports and the specific, but sometimes overlapping, roles adopted by examiners provided fertile ground for utilizing the 'Ways of Knowing' thesis proposed by Habermas $(1972 ; 1974)$ as a means of deepening analysis. An analysis that tried to match the above perceived examiner roles with the Habermasian thesis was then undertaken. This will be explained below in full, first by spelling out clearly those features of the Habermasian thesis that were utilized and their more obvious implications for the tenor of the project.

\section{Ways of knowing and the moveable relationships of the examiner and candidate}

Consistent with the earlier analysis of examiner roles, part of this later analysis centred on the ways in which Habermas's three ways of knowing positioned the participants in a particular kind of teaching/learning relationship (Holbrook et al., 2004b; Lovat et al., 2004). In this case, the relationship was between the examiner and candidate or, later, between the examiner and the candidate's supervisor, sometimes with the candidate in the middle. Where the focus was simply on the examiner and the candidate, text connoting empirical-analytic knowing seemed to be accompanied by an examiner role best described as "expert", with the candidate kept well and truly in a subservient role. Where historical/hermeneutic knowing seemed operative, the role was titled as 'partner', with a more even-handed relationship being apparent between the examiner and the candidate. Finally, when knowing of the critical/selfreflective type emerged, albeit with extreme rarity, the traditional roles of examiner and candidate were marked by a true intellectual equability, a veritable meeting of minds wherein actual role reversal seemed possible. Signs of this were in the explicit mention of the candidate as being so much in control of her/his knowing that the role of the examiner transformed to one best described as 'listener' and even 'learner'. This relationship seemed to be marked by what Van Manen (1977), in attempting to characterize the relationship that best fits Habermas's third way of knowing, described as "no asymmetry". By enabling this position, the examiner relegated the customary power associated with the process of examination, choosing to acknowledge her/his having actually learned through the process.

At the heart of Habermas's thesis is the notion that self-reflective knowing is impelled by a cognitive interest to be 'emancipated', or free in our knowing. This way of knowing is therefore characterized by an intensive critique of all of the assumptions and sources of our knowing up to that point in time. Among the assumptions and sources of knowing are those of both the external and internal world. Externally, one confronts one's enculturated past, one's corporate beliefs and community values, one's family, school, political and religious heritage. Internally, one confronts one's self. Through critical, self-reflective knowing, one is challenged to let go of much of the past and to embrace new futures. The end of critical, self-reflective knowing is to be found in praxis, practical action for change. This results from the fact that one cannot remain in the same place once one has confronted one's past and one's self. The ramifications for the $\mathrm{PhD}$ study taken from this is that critical/ self-reflective knowing is the kind of knowing that one might expect to be most evident in a learning regime that is purportedly about work we variously describe as 'an original contribution', 'creative', 'innovative' or 'incorporating new understandings'. In other words, granted the over-riding and virtually universal objective of the $\mathrm{PhD}$ to impel change and stretch the boundaries of our knowledge, logic would suggest that there would be a surfeit of examination text conforming 
to Habermas's critical and self-reflective knowing, at least when dealing with theses clearly regarded as being of the best kind.

\section{Applying the Habermasian Thesis}

In this light, special attention was paid to those thesis reports that were clearly rated at the top end of the reports under consideration, with the examiner's apparent positioning against the candidate being the focus (cf. Lovat, 2004; Lovat et al., 2004). This constituted about 5\% of the 804 theses. In a later study (cf. Monfries \& Lovat, 2006), about half of these (number 23) would be subject to even more intense analysis. Here, the coding under 'formative' and 'summative' discussion became especially important. Three researchers read the reports, highlighting textual excerpts that were thought to represent the three Habermasian perspectives. Excerpts selected by at least two of the researchers were selected for further analysis and, finally, agreement that they did indeed match the assumptions connoted by the three perspectives. The result demonstrated that the primary mode of assessment across all theses, regardless of the final result conferred, fell more obviously within the bounds of 'expert' text, with little 'partnership' text and almost no text which confirmed the logic that good PhDs should be heralded by a surfeit of text that Van Manen (1997) described as 'nonasymmetrical'. Within the 'expert' text were, predictably, high proportions of formative comments, where the examiner was either attempting to teach the candidate how some aspect of the thesis could have been improved or was being explicit in pointing to some error. In other words, there was a pervading theme of deficit that seemed to dominate the average examination report, almost regardless of the final estimation of its quality.

An example provided in Lovat (2004) showed that, even when dealing with 'top box' (unqualified pass) theses, the preponderance of negative text could be striking. One case study of such a thesis illustrated three highly castigatory examination reports, with comments including: "shortcomings in the way the thesis is argued”, “... analysis which is very limited in scope”, “... does not deal with the arguments”, “... without an acknowledgment of its underlying arguments”, “... understandings are so limited”, “... reading ... is very limited”, "Most important are weaknesses in the structure of the thesis". In spite of such derisory assessment, all three examiners, by recommending a 'top box' pass, presumably rated the thesis as constituting a major contribution to the world of public knowledge. This serves to illustrate the point that, in the $\mathrm{PhD}$ examination report, we may more often than not be dealing with a particular type of text, a virtual literary genre, born of assumptions about the nature of the task and its incumbent duties, as well as about the relationship between the examiner and the student

As suggested, few reports developed a discourse that could be described as partnership, collegiality or symmetry, and there was a marked absence of the awe that logic would suggest one might find to be commonplace if examiners were witnessing original and significant contributions to knowledge. Only one report (of all 2121 reports) testified to what here is defined as 'awe'. It began with the words: "There are those pleasant occasions when one is asked to ... examine a thesis and you wish that you had written it. I believe that this is one of those experiences." In contrast to this kind of accolade, even in the 5 per cent (of 804) of candidates whose reports were all rated as 'top box' (that is, an unqualified pass), evidence was that examiners still tended to function from a position of expertise and to include in their reports either negative comments or comments strongly directed towards how the thesis might have been improved (cf. Holbrook et al., 2004c). This appeared to confirm the earlier finding noted above that $46 \%$ of reports engaged in quite explicit negative judgement, even 
though the majority of these reports went on to recommend an unqualified or marginally qualified pass.

The above phenomenon led to the postulation that, in the $\mathrm{PhD}$ examination report, we may be dealing with a virtual literary genre, born of assumptions about the nature of the task and its incumbent duties, and built up over time to become a set of expectations attached to an informal yet quietly prescriptive aspect of academic culture (Lovat, 2004). If this were so, it would suggest that examination reports may largely be constructed according to this genre, with the quality of work under examination being of secondary rather than primary determining power. The case has further been made that, were such a dominant genre in the examination script revelatory of the entire regime of the $\mathrm{PhD}$, the potential was there for routine discouragement and even obstruction of the 'originality' and 'new contribution' factor that is meant to be its over-riding item of assessment. Again, this is working on the assumption, informed by the Habermasian thesis, that a $\mathrm{PhD}$ regime replete with boundary shaking and original contributions should be evidenced by an examination genre that is fairly well filled with positive comment and robust self-reflective script. In fact, the evidence arising from examiner-candidate text seemed to show clearly that the dominant way of knowing, and the relationships constructed in the reports, betrayed that a far narrower and more minimalist regime was in place.

In further work, Lovat et al. (2004) concentrated on texts that included explicit reference to the role of the supervisor, concluding that the dominance of the 'empirical-analytic' way of knowing appeared to persist but that there was a greater number of instances where the examiner seemed willing to move from the expertise regime towards one of partnership and, on occasion, verging towards the self-reflective, although nowhere to the extent of the one report (of 2121 reports) noted above. It was surmised that the majority of those examiner comments that explicitly referred to the supervisor were focussed on 'custodial' work, or what was named as 'expertise' text. The relationship constructed examiner and candidate/supervisor within a hierarchy, complete with clear inequality and asymmetry. The hierarchical implications were two-fold, as examiners either positioned themselves over supervisors, or positioned both themselves and the supervisor over the candidate. The examiner, positioned as expert and custodian of a body of technical and conventional knowing, often outlined to both supervisors and candidates the ways in which the thesis should have conformed to unmet standards of presentation and reproductions of particular bodies of knowledge (e.g., developing a sufficiently broad literature review, appropriate methodology and accurate application of it, more careful, accurate and/or meaningful interpretation of the results, etc.). An example of such a text was: "Both the candidate and supervisors (should) remedy these aspects before final acceptance”.

At times, the examiner's authority over the supervisor was exerted through reprimanding the latter about the quality of the thesis. In these texts, the custodial gaze of the 'expert' was clearly directed beyond the candidate to the supervisor who sat behind. In terms of direct instructions to supervisors or negative comments about supervision, much of the examiner's language articulated clear expectations that a primary role of the supervisor was to ensure that the thesis under examination was of an appropriately high technical standard. When this did not occur, the hierarchy between examiners and supervisors was evident in the examiner's directions. For example, one examiner commented that “ ... a final and careful proof-reading from the supervisors is required.” While another commented on more serious statistical oversights that needed to be addressed during future supervision: "I strongly urge these 
advisors to get their students to use ... and to show ... henceforth. They should at least insist on ...”

Such comments seem to indicate that the process of doctoral examination can be as much an examination of the supervisor's expertise as of the ability of the candidate and the quality of the thesis. Supervisors are therefore reproached, sometimes quite severely, when they have not been sufficiently meticulous in their duty of guiding the thesis to conform to appropriate standards, have provided insufficient guidance, or have failed to adequately perform in some other way, as indicated in the comments below:

I note that the candidate has not had the benefit of direct supervision by an expert in the field and therefore believe that responsibility for the ultimate product does not solely lie with the candidate.

All of the above matters should have been dealt with during the draft stages of the thesis and reflect badly on the supervisor more so than the candidate.

Hence, it was concluded that the same preponderantly 'expertise' text identified in the earlier work regarding the positioning of the examiner in relation to the candidate extended to the role of the supervisor as well. This supposition would seem to strengthen the thesis that there may be a de facto genre in play in the phenomenon of the examination report. If so, this genre implicitly positions the supervisor in an expert role against the candidate. Indeed, examiner expertise text tended more often than not to blur any distinction between comments made about inadequate supervision and the implicit assumption that the main role of the supervisor was a custodial one. Within this text, there tended to be no allowance made for other conceptions of the supervisor role. Nor was there much evidence of the extension of that mercy that was occasionally offered to the candidate being also offered to the supervisor. In other words, for poor supervision, there were no excuses and the tone of expertise text directed at the supervisor actually appeared stronger and harsher than when applied directly to the candidate.

\section{Ramifications for Supervisors and their Candidates}

Overall, 22 per cent of examiners referred to the supervisor at least once in their report, the average varying between 18 and 25 per cent, depending on the Broad Field of Study of the thesis. Acknowledgement of some different positioning on the part of the examiner, when conscious of the role of the supervisor in supervising a thesis judged positively, does not subvert the earlier postulation that the 'empirical-analytic' way of knowing is the relatively dominant mode employed in all examination reports, and that this is the case whether the supervisor is drawn into the equation or not. Indeed, the persistence of expertise text, even amidst slightly more positive comments, merely serves to deepen the suspicion that a technical and fairly constrained regime may have become institutionalized within the $\mathrm{PhD}$ examination culture. Again, it is suggested that such text may constitute what might be described as an 'examination genre' and that, granted the stated intentions of the $\mathrm{PhD}$ to be 'original', 'creative', 'contributing to new knowledge', etc, such a genre could serve unwittingly to discourage the kind of risk-taking and innovation that would normally be attached to such a venture. Just as the genre might serve ultimately to discourage candidates as they become aware of the examination regime implied by the genre, so too might supervisors focus overly in their own work with the candidate on the technical features germane to empirical/analytic knowing, rather than encourage overly the 
historical/hermeneutic or critical/self-reflective potential of a thesis. In other words, knowing that a fairly technical and negative genre is likely to dominate the examination process may well encourage supervisors to play safe in the mentoring of the thesis, rather than risk too much of the kind of boldness normally found as an attachment to true stretching of the boundaries of knowledge.

At the same time, it may be important for candidates and their supervisors to take note of the fact that, at least on the surface of it, text classified as 'historical-hermeneutic' seems to be in greater abundance when the examiner is seen to draw explicitly on the role of the supervisor, and that this text was wrapped in more positive and encouraging language, implied a different positioning and invited a modicum of partnership in the business of assessing the value of the thesis. Furthermore, the findings indicate that there was at least some enhancement of a disposition on the part of the examiner towards critical and self-reflective knowing when the supervisor was drawn into the equation, so moving the positioning between examiner, supervisor and candidate more towards one of 'non-asymmetry' and even occasional awe at the emergence of new knowing. As illustrated above, the greater number of such texts than were found when the examiner/candidate role alone was in focus may reveal an enhanced disposition on the part of examiners to relegate some power over the process to the supervisor, while still being guarded about doing so to the candidate. One of the ramifications from this finding for research training may be that the role of the supervisor is more instrumental in the final assessment process than has previously been recognized. It would normally be assumed as a truism that positive and contributive supervision is important for the process of assembling the thesis but, once the thesis has been moved out to examination, the role of the supervisor is normally regarded as expended. It may be, however, that the role is actually extended and that the supervisor continues to play some shadowy role in and behind the thesis under examination. There may be an indication in these findings that some examiners, at least, are more prepared to relinquish their own expert positioning and engage more wholeheartedly with the thesis if the role that the supervisor has played is obvious.

\section{Conclusion}

In summary, the PhD Examinations Project is at the point of considering seriously that, even when faced with a very good thesis, examiners appear to be heavily influenced by a culture, implicit if not explicit, that is disposed towards the technical and, more often than not, negative aspects of assessment. Where the role of the supervisor is explicit, and the thesis result is good, it seems that some examiners, at least, feel more prepared to relinquish this technical and fairly negative mode of assessment in favour of a more accommodating and even equable mode, allowing for more generous comment and, occasionally, for acknowledgment that the thesis was of personal benefit to them as examiners. Even more rare, but nonetheless present when the supervisor's role was made explicit, was an expression of that awe on the part of the examiner that we might expect as an accompaniment to a work of originality and contribution.

At the more basic levels of preparation for presentation, findings that reveal a pattern of emphasis by examiners on technical correctness would suggest that doctoral candidates should leave no stone unturned in assuring the technical purity of their final work, be it in terms of grammar and syntax, lay-out, content, expression or methodological accuracy. Moreover, if the findings from this study are well founded that examiner text tends towards the negative as a virtual genre, then candidates need to be prepared for this reality in order to 
avoid unnecessary disappointment and possible confidence loss when the work on which they have laboured so hard is subject to abject criticism regardless of its overall worth. At a more subtle level, if the supposition contained herein is sustained by further evidence that an obvious and positive role having been played by supervision tends towards softening or appeasing the judgment of the examiner, there are huge ramifications for the role that supervisors might play in sharing the task of constructing the thesis for examination.

Finally, the study has illustrated the need for further defining and refining of the notions of 'originality' and 'creativity' that underlie the doctoral regime. If it could be argued and demonstrated that the examination scripts in hand do not in fact represent a 'technical' and 'negative' genre but are true and authentic estimations of the levels of originality and creativity being displayed, then the obvious conclusion to be drawn is that the doctoral regime is not working in fact to produce the new knowledge purported of it. In turn, this would lead to querying whether, in an era that has seen 'doctorateness' transformed from a relative rarity to a veritable industry, with funding-related pressure on universities to move candidates in and through to completion in minimum time, the $\mathrm{PhD}$ has in fact been tamed of its 'wild side', namely those more creative and original contributions that might extend the duration of candidacy and be seen as riskier propositions at examination time. Could it be that the modern $\mathrm{PhD}$ is bereft of its essential purpose?

\section{References.}

Bourke, S., Hattie, J. \& Anderson, L. (2004). Predicting examiner recommendations on $\mathrm{PhD}$ theses. International Journal of Educational Research, 41, 178-194.

Bourke, S., Holbrook, A. \& Lovat, T. (2007 in press). Examiners and examination outcomes. In C. Denholm \& T. Evans (eds.). Supervising doctorates downunder: Keys to effective supervision in Australia and New Zealand. Melbourne: ACER Press.

Delamont,S., Atkinson, P. Parry, O. (1997). Supervising the PhD: A guide to success. Buckingham: SRHEOUP.

Denicolo, P. (2003). Assessing the PhD: A constructive view of criteria. Quality Assurance in Education, 11, 84-91.

Elton, L.(2004). A challenge to established assessment practice. Higher Education Quarterly, $58,43-62$.

Habermas, J. (1972). Knowledge and human interests. (transl. J. Shapiro) London: Heinemann.

Habermas, J. (1974). Theory and practice. (transl. J. Viertal) London: Heinemann.

Holbrook, A. (2001). PhD examination-Assessment's least mapped frontier. Paper presented at Annual Conference of the Australian Association for Research in Education (AARE), Fremantle, Australia, December, 2-6. Available at http://www.aare.edu.au/01pap/hol01587.htm [Accessed 29 August 2006] 
Holbrook, A., Bourke, S., Farley, P., \& Carmichael, K. (2001). Analysing PhD examination reports and the links between PhD candidate history and examination outcomes: A methodology. Research and Development in Higher Education, 24, 51—61.

Holbrook, A., Bourke, S., \& Dally, K. (2003). How examiners define quality in the doctoral thesis. Paper presented at the 10th Biennial Conference of the European Association for Research on Learning and Instruction (EARLI), Padova, Italy, August 26-30.

Holbrook, A. \& Bourke, S. (2004). An investigation of PhD examination outcome in Australia using a mixed method approach. Australian Journal of Educational and Developmental Psychology, 4, 153-169.

Holbrook, A., Bourke, S., Lovat, T. \& Dally, K. (2004a). Qualities and characteristics in the written reports of doctoral thesis examiners. Australian Journal of Educational and Developmental Psychology, 4, 126-145.

http://www.newcastle.edu.au/group/ajedp/Archive/Volume_4/current/v4-holbrook-et-al.pdf [Accessed 29 august 2006]

Holbrook, A., Bourke, S., Lovat, T. \& Dally, K. (2004b). PhD theses at the margin: Examiner comment on re-examined theses. Melbourne Studies in Education, 45, 89-115.

Holbrook, A., Bourke, S, Lovat, T. \& Dally, K. (2004c). An investigation of doctoral examination reports. International Journal of Educational Research, 41, 98-120.

Holbrook, A., Bourke, S., Fairbairn, H. \& Lovat, T. (2007 in press). Examiner comment on the literature review in $\mathrm{PhD}$ theses. Studies in Higher Education, 32.

Jackson, C. \& Tinkler, P (2001). Back to basics: a consideration of the purposes of the PhD viva. Assessment \& Evaluation in Higher Education, 26, 355-366.

Johnston, S. (1997). Examining the examiners: an analysis of examiners' report on doctoral thesis. Studies in Higher Education, 22, 333-347.

Kiley, M. \& Mullins, G. (2004).Examining the examiners. How inexperienced examiners approach the assessment of research theses. International Journal of Educational Research, $41,121-35$.

Kouptsov, O. (1994). The Doctorate in the Europe Region. CEPES UNESCO.

Lawson, A., Marsh, H., \& Tansley, T. (2003). Examining the examiners. Australian Universities Review, 46, 32-36.

Lovat, T. (2004). 'Ways of knowing' in doctoral examination: How examiners position themselves in relation to the doctoral candidate. Australian Journal of Educational and Developmental Psychology, 4, 146-152.

http://www.newcastle.edu.au/group/ajedp/Archive/Volume_4/v4-lovat.pdf [Accessed 29 August 2006]

Lovat, T., Holbrook, A., Bourke, S., Dally, K., \& Hazel, G. (2002). Examiner comment on theses that have been revised and re-submitted. Paper presented at Annual Conference of the 
Australian Association for Research in Education (AARE), The University of Queensland, Brisbane, 2-5. Available at http://www.aare.edu.au/02pap/lov02282.htm [Accessed 29 August 2006]

Lovat, T., Monfries, M. \& Morrison, K. (2004). Ways of knowing and power discourse in doctoral examination. International Journal of Educational Research, 41, 163-177.

Monfries, M. \& Lovat, T. (2006). Power discourse in PhD examination reports: A crossdisciplinary analysis. Paper presented at Annual Conference of the Australian Association for Research in Education (AARE), The University of Adelaide, Adelaide

Morley, L., Leonard, D. \& David, M. (2002). Variations in vivas: Quality and equality in British PhD assessments. Studies in Higher Education, 27, 263-273.

Mullins, G. \& Kiley, M. (2002). 'It's a PhD, not a Nobel Prize': How experienced examiners assess research theses. Studies in Higher Education, 27, 369-386.

Pitkethly, A. \& Prosser, M. (1995). Examiners' comments on the international context of PhD theses. In C. McNaught \& K. Beattie (Eds.) Research into higher education: Dilemmas, directions and diversion. Melbourne: HERDSA.

Powell, S. \& Green, H. (2003). Research degree examining: Quality issues of principle and practice. Quality Assurance in Education, 11, 55-63.

Scott, D. Brown, A., Lunt, I \& Thorne L (2004). Professional doctorates. Integrating professional and academic knowledge. Berkshire: SHRE and Open University Press.

Shaw, M. \& Green, D. (2002). Benchmarking the PhD: A tentative beginning. Quality Assurance in Education, 10, 116-124.

Tinkler, P. \& Jackson, C. (2000). Examining the doctorate: Institutional policy and the PhD examination process in Britain. Studies in Higher Education, 25, 167-180.

Tinkler, P., \& Jackson, C. (2002). In the dark? Preparing for the PhD viva. Quality Assurance in Education, 10, 86-97.

Tinkler, P. \& Jackson, C. (2004). The doctoral examination process: A handbook for students, examiners and supervisors. Berkshire, UK: Society for Research into Higher Education.

Trafford , V. (2003), Questions in doctoral vivas: Views from the inside. Quality Assurance in Education, 11, 113-121.

Winter, R., Griffiths, M. \& Green, K. (2000). The 'academic' qualities of practice: What are the criteria for a practice-based PhD.? Studies in Higher Education, 25, 25-37.

Van Manen, M. (1977). Linking ways of knowing with ways of being practical. Curriculum Inquiry, 6, 205-228. 
TABLE 1: Prevalence of text coding categories in examiner reports

\begin{tabular}{|c|c|c|}
\hline TEXT CODING CATEGORIES & $\begin{array}{c}\text { Occurrence } \\
\text { in (\%) of reports }\end{array}$ & $\begin{array}{l}\text { Proportion of } \\
\text { text (mean \%) }\end{array}$ \\
\hline \multicolumn{3}{|l|}{ EXAMINER AND PROCESS } \\
\hline Personal \& professional context & 50 & 5 \\
\hline Application of anticipated criteria & 61 & 5 \\
\hline The model PhD & 14 & 1 \\
\hline Mention of supervisor(s) & 22 & 1 \\
\hline \multicolumn{3}{|l|}{ ASSESSABLE AREAS COVERED } \\
\hline Scope of thesis & 73 & 8 \\
\hline Significance \& contribution of thesis & 82 & 10 \\
\hline Publications arising & 44 & 3 \\
\hline Existing publications & 13 & 1 \\
\hline Review of literature: Breadth/depth/recency & 70 & 6 \\
\hline Review of literature: Inaccuracy & 30 & 2 \\
\hline Review of literature: Use/application & 38 & 3 \\
\hline Approach: method/design/execution & 81 & 13 \\
\hline Analysis \& reporting of findings & 95 & 37 \\
\hline Topic related issues & 28 & 5 \\
\hline Communicative competence: Substantial & 79 & 6 \\
\hline Communicative competence: Editorial & 57 & 8 \\
\hline \multicolumn{3}{|l|}{ DIALOGIC ELEMENTS } \\
\hline Intellectual engagement with topic/subject & 21 & 3 \\
\hline Conversation with the reader & 30 & 3 \\
\hline Use of first person & 89 & 17 \\
\hline \multicolumn{3}{|l|}{ EVALUATIVE ELEMENTS } \\
\hline Summative assessment: Positive & 87 & 19 \\
\hline Summative assessment: Neutral & 47 & 4 \\
\hline Summative assessment: Negative & 33 & 2 \\
\hline Formative instruction: & 63 & 21 \\
\hline Other instruction: Commentary & 64 & 10 \\
\hline Other instruction: Prescription & 64 & 11 \\
\hline Other judgment: Positive & 72 & 10 \\
\hline Other judgment: Neutral & 30 & 2 \\
\hline Other judgment: Negative & 32 & 2 \\
\hline LENGTH OF REPORTS (LINES) & . & 132 \\
\hline
\end{tabular}

